\title{
Histiocitosis de células de Langerhans
}

\section{Langerhans cell histiocytosis}

\author{
J. Rojo Álvaro' ${ }^{1}$, S. Pérez Ricarte ${ }^{1}$, M. Alfonso Imízcoz ${ }^{2}$, S. Curí Chércoles ${ }^{2}$, \\ M. Hernández Bonaga ${ }^{2}$, B. Fernández Infante ${ }^{2}$.
}

\section{RESUMEN}

Se describe el caso de un varón con diagnóstico de histiocitosis de células de Langerhans. La histiocitosis $\mathrm{X}$ es una enfermedad intersticial con una incidencia real y una prevalencia desconocidas que puede sospecharse por datos epidemiológicos y radiológicos. El diagnóstico puede realizarse mediante BAL y/o estudio anatomo-patológico de biopsia. El principal tratamiento consiste en abandonar el hábito tabáquico. La evolución puede ser variable.

Palabras clave. Histiocitosis X. Células de Langerhans. Enfermedad pulmonar intersticial.

\begin{abstract}
We describe the case of male diagnosed with histiocytosis of Langerhans cells. Histiocytosis $\mathrm{X}$ is an interstitial disease with a real incidence and an unknown prevalence that can be suspected due to epidemiological and radiological data. The diagnosis can be realized using BAL and/or anatomo-pathological study of a biopsy. The principal treatment is to give up the tobacco habit. Evolution can be favourable.
\end{abstract}

Key words. Histiocytosis X. Langerhans cell. Interstitial lung disease.
1. Servicio de Medicina Interna. Complejo Hospitalario de Navarra. Pamplona.

2. Servicio de Neumología. Complejo Hospitalario de Navarra. Pamplona.

Recepción: 8 de octubre de 2013

Aceptación provisional: 18 de noviembre de 2013

Aceptación definitiva: 10 de diciembre de 2013

\section{Correspondencia:}

Jorge Rojo Álvaro

Servicio de Medicina Interna

Complejo Hospitalario de Navarra

C/ Irunlarrea, 3

31008 Pamplona (Navarra)

E-mail: jorgerojo23@hotmail.com 


\section{INTRODUCCIÓN}

La patología intersticial es muy amplia, incluye más de 100 enfermedades que afectan al espacio intersticial pulmonar. Estas enfermedades tienen características clínicas, radiológicas y funcionales comunes y ciertos caracteres que las diferencian ${ }^{1,2}$. El diagnóstico suele precisar material histológico $^{3,4}$. El lavado broncoalveolar (BAL) rara vez es diagnóstico ${ }^{5,6}$. Entre estas enfermedades se encuentra la histiocitosis $\mathrm{X}$ o de células de Langerhans.

A continuación presentamos un caso clínico con el objetivo de aportar nuestra experiencia diagnóstico-terapéutica y revisar el diagnóstico diferencial de la patología intersticial pulmonar.

\section{CASO CLÍNICO}

Se trata de un varón de 35 años de edad que acudió a consulta remitido para valoración de alteración radiológica de tórax. No tenía alergias medicamentosas, era alérgico al polen. De profesión trabajaba colocando paneles de pladur. Fumaba 10 cigarrillos/día desde los 14 años (10,5 paquetes/año) y 8 porros de marihuana/día. Consumía alcohol de forma ocasional. No tenía antecedentes familiares de interés. Interrogado refería en el último año tos de predominio vespertino y nocturno con el decúbito supino, acompañada de expectoración blanca. Además presentaba sibilancias asociadas que mejoraban con broncodilatadores. También refería sensación disneica con

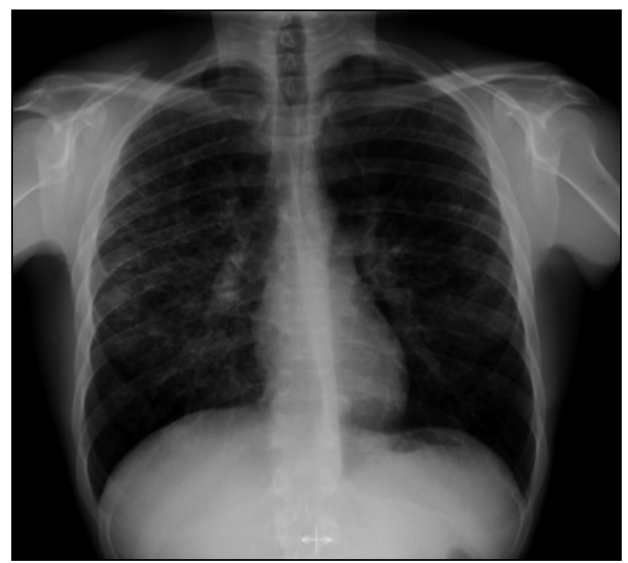

Figura 1. Rx tórax. los esfuerzos. Había perdido unos $5 \mathrm{Kg}$ de peso. Refería astenia que relacionaba con el trabajo. Tenía un perro en el domicilio. No había realizado viajes recientemente ni había tenido contactos conocidos con pacientes tuberculosos.

A la exploración física presentaba buen estado general, eupneico con una saturación basal de oxígeno del $98 \%$. No tenía adenopatías ni acropaquias. La auscultación cardiopulmonar era normal.

La radiografía ( $\mathrm{Rx}$ ) de tórax (Fig. 1) mostraba un patrón intersticial lineal difuso de predominio derecho. Se completó el estudio con varias exploraciones complementarias: análisis de sangre con todos los parámetros dentro de la normalidad, incluida autoinmunidad y serologías negativas, pruebas de función respiratoria (PFR) dentro de la normalidad, Mantoux negativo, tomografía computarizada (TC) de tórax (Fig. 2) que mostraba el parénquima pulmonar ocupado por múltiples lesiones cavitadas-quísticas, de pequeño tamaño y ampliamente distribuidas por ambos campos pulmonares, con afectación tanto de campos superiores como inferiores.

Con estos hallazgos se realizó broncoscopia sin apreciar alteraciones ni lesiones de la mucosa. Se realizaron tres BAL en el lóbulo superior derecho, que fueron remitidos para estudio citológico, baciloscopia y de subpoblaciones linfocitarias. Además se realizaron cuatro broncoaspirados de secreciones (BAS) para hongos, Pneumocystis, cultivo y bacilo de Koch. Todos los resultados fueron negativos. El informe anatomopatológico del broncoaspirado reveló mínimo componente inflamatorio, sin histiocitos anómalos ni células atípicas. La inmunohistoquímica resultó negativa para S100 y CD1a.

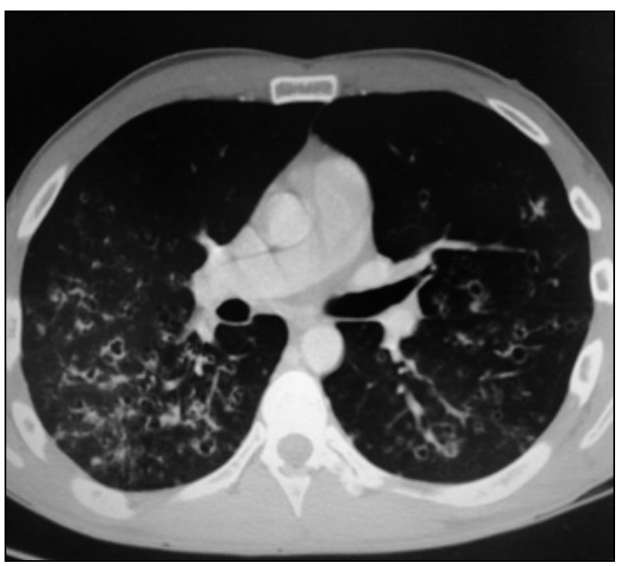

Figura 2. TC tórax. 
Dado el resultado se procedió a realizar biopsia del lóbulo pulmonar superior derecho mediante toracotomía. La anatomía patológica fue compatible con una histiocitosis de Langerhans en fase proliferativa o fase celular.

Se recomendó al paciente el abandono del hábito tabáquico. Fue revisado en consulta 3 meses después y refería encontrarse asintomático con ganancia de $6 \mathrm{~kg}$. No obstante, en la Rx de tórax de control permanecía el patrón intersticial.

\section{DISCUSIÓN}

La patología intersticial es muy amplia, incluye más de 100 enfermedades que afectan al espacio intersticial, localizado entre la membrana basal del epitelio alveolar y el endotelio capilar, en el que se encuentran en condiciones normales células (macrófagos, fibroblastos, miofibroblastos...) y componentes de la matriz (colágeno, fibronectina, etc.). Estas enfermedades tienen características clínicas, radiológicas y funcionales comunes y ciertos caracteres que las diferencian y orientan hacia su etiología ${ }^{1,2}$.

El diagnóstico suele precisar material histológico que puede obtenerse por biopsia transbronquial, por toracoscopia o mediante toracotomía ${ }^{3,4}$. El BAL solo es diagnóstico en la linfangitis carcinomatosa, el carcinoma de células alveolares, el linfoma, la neumonía por Pneumocystis carinii, la histiocitosis X y la proteinosis alveolar ${ }^{5,6}$.

La clasificación de las enfermedades intersticiales se define en función de su etiología. Pueden ser secundarias a una causa identificable o idiopáticas. Una variedad de infecciones puede causar afectación intersticial, desde infecciones fúngicas (coccidiomicosis, criptococosis, neumocystis) hasta neumonías bacterianas atípicas y neumonías virales. La causa más frecuentemente identificable es la exposición ocupacional y a agentes del entorno, especialmente polvos inorgánicos y orgánicos, toxicidad pulmonar por fármacos y daño pulmonar por radioterapia $^{7}$. La mayoría de las conectivopatías también puede afectar el pulmón (dermatopolimiositis, artritis reumatoide, lupus, esclerodermia, síndrome de Sjögren, espondilitis anquilosante, enfermedad mixta del tejido conectivo). Entre las causas idiopáticas se encuentran la sarcoidosis y las neumonías idiopáticas intersticiales ${ }^{1,2,8}$. Dentro de las neumonías intersticiales idiopáticas, la neumonía intersticial usual o fibrosis pulmonar idiopática se caracteriza por tos y disnea de esfuerzo de más de 6 meses de evolución, crepitantes secos en las bases y con frecuencia acropaquias. En la radiografía de tórax se aprecia patrón intersticial de predominio basal. En el TC se aprecia engrosamiento de septos y zonas de panal en bases.

Otra enfermedad intersticial es la linfangioleiomiomatosis. Es una enfermedad exclusiva de mujeres en edad fértil. Cursa con quistes diseminados, patrón intersticial con volúmenes altos, obstrucción con difusión pulmonar de monóxido de carbono (DLCO) baja y son frecuentes el neumotórax y el derrame pleural (quilotórax).

Diferentes fármacos pueden causar afectación pulmonar: amiodarona, busulfán, bleomicina, metotrexate, nitrofurantoína, etc.

La proteinosis alveolar se produce al acumularse en los alvéolos un material proteináceo PAS positivo rico en fosfolípidos. Cursa con disnea de evolución lentamente progresiva y tos seca. Implica riesgo de infecciones por Nocardia, Mycobacterium avium y Pneumocystis carinii. El tratamiento consiste en hacer un BAL completo.

La histiocitosis de células de Langerhans es un raro desorden histiocítico cuya incidencia real se desconoce. La enfermedad es más común en niños de 1 a 3 años. $\mathrm{La}$ incidencia se estima que es de 3 a 5 casos/millón en niños y de 1 a 2 casos/millón en adultos. La afectación pulmonar es rara y se produce en adultos jóvenes; se asocia casi universalmente al tabaquismo mientras que la afectación extrapulmonar no parece tener relación con el tabaco ${ }^{9,10}$.

La célula de Langerhans es una célula diferenciada de la estirpe monocito-macrófago y es la célula patológica. Por microscopía electrónica se identifican los clásicos gránulos de Birbeck. Presenta inmunohistoquímica positiva para la proteína $\mathrm{S} 100$ y para el antígeno de superficie $\mathrm{CD} 1 \mathrm{a}^{11}$. Con frecuencia, la enfermedad se localiza en la mitad superior de los pulmones, en con- 
traste con la afectación basal típica en la fibrosis pulmonar idiopática. Las lesiones a menudo se extienden ampliamente por el parénquima pulmonar rodeando estructuras broncovasculares, dando lugar a las características lesiones estrelladas de la enfermedad. La fibrosis intersticial y la formación de pequeños quistes ocurren con la enfermedad avanzada. Los pacientes pueden presentar neumotórax espontáneo de repetición, tos seca, disnea, síntomas constitucionales como fiebre o pérdida de peso. También pueden presentar afectación extrapulmonar con diabetes insípida, lesiones óseas quísticas e hipertensión pulmonar (HTP) $)^{9,10,12}$. El TC torácico de alta resolución muestra múltiples nódulos y quistes de forma predominante en campos superiores y un patrón intersticial ${ }^{13}$. La tomografía por emisión de positrones (PET) puede mostrar captación aumentada en etapas iniciales de la enfermedad con predominio de lesiones nodulares ${ }^{14}$. Las PFR pueden ser normales o mostrar volúmenes reducidos con una disminución de la DLCO. La presencia de un patrón obstructivo aparece típicamente en pacientes con enfermedad quística avanzada. Si el estudio radiológico no es diagnóstico, la combinación de la biopsia transbronquial y el BAL mostrando un incremento del número de células CD1a positivas sugiere fuertemente el diagnóstico ${ }^{9,10}$. El principal tratamiento consiste en abandonar el hábito tabáquico. Solo los pacientes con predominio de nódulos responden al empleo de corticoides. La radioterapia no es útil para el tratamiento de la enfermedad pulmonar. La historia natural de la enfermedad es variable; algunos pacientes experimentan remisión espontánea mientras que otros progresan hasta estadios finales con extensa fibrosis. Los pacientes que dejan de fumar por lo general mejoran. La HTP es frecuente y está asociada de forma independiente con el descenso de la supervivencia. La media de supervivencia es de 12,5 años desde el diagnóstico. La supervivencia libre de enfermedad a los 5 y 10 años es de 74 y $64 \%$ respectivamente. Cerca de la mitad de las muertes se deben a fallo respiratorio. El seguimiento trimestral durante el primer año tras el diagnóstico puede ser útil para identificar a aquellos pacientes en riesgo de desarrollar enfermedad progresiva ${ }^{12}$.

\section{BIBLIOGRAFÍA}

1. Ryu JH, Olson EJ, Midthun DE, Swensen SJ. Diagnostic approach to the patient with diffuse lung disease. Mayo Clin Proc 2002; 77: 1221-1227.

2. KING TE JR. Clinical advances in the diagnosis and therapy of the interstitial lung diseases. Am J Respir Crit Care Med 2005; 172: 268-279.

3. Bradley B, Branley HM, Egan JJ, Greaves MS, HaNSELL DM, HARRISON NK et al. Interstitial lung disease guideline: the British Thoracic Society in collaboration with the Thoracic Society of Australia and New Zealand and the Irish Thoracic Society. Thorax 2008; 63 Suppl 5: v1-58.

4. RAGHU G. Interstitial lung disease: a diagnostic approach. Are CT scan and lung biopsy indicated in every patient? Am J Respir Crit Care Med 1995; 151: 909-914.

5. KINDER BW, Wells AU. The art and science of diagnosing interstitial lung diseases. Am J Respir Crit Care Med 2009; 179: 974-975.

6. Ohshimo S, Bonella F, Cui A, Beume M, Kohno N, GuZman J et al. Significance of bronchoalveolar lavage for the diagnosis of idiopathic pulmonary fibrosis. Am J Respir Crit Care Med 2009; 179: 1043-1047.

7. Glazer CS, Newman LS. Occupational interstitial lung disease. Clin Chest Med 2004; 25: 467-468.

8. PIPAVATH S, Godwin JD. Imaging of interstitial lung disease. Clin Chest Med 2004; 25: 455-465.

9. TAZI A. Adult pulmonary Langerhans' cell histiocytosis. Eur Respir J 2006; 27: 1272-1285.

10. ARICò M, GirSChIKOFSKY M, GÉNÉREAU T, KLERSY C, McClaIN K, GroIs N et al. Langerhans cell histiocytosis in adults. Report from the International Registry of the Histiocyte Society. Eur J Cancer 2003; 39: 2341-2348.

11. Allen CE, Li L, Peters TL, Leung HC, Yu A, Man TK et al. Cell-specific gene expression in Langerhans cell histiocytosis lesions reveals a distinct profile compared with epidermal Langerhans cells. J Immunol 2010; 184: 4557-4567.

12. Abla O, Egeler RM, Weitzman S. Langerhans cell histiocytosis: Current concepts and treatments. Cancer Treat Rev 2010; 36: 354-359.

13. Tazi A, Marc K, Dominique S, de Bazelaire C, CrestaNI B, ChInET T et al. Serial computed tomography and lung function testing in pulmonary Langerhans' cell histiocytosis. Eur Respir J 2012; 40: 905-912.

14. Krajicek BJ, Ryu JH, Hartman TE, Lowe VJ, Vasallo R. Abnormal fluorodeoxyglucose PET in pulmonary Langerhans cell histiocytosis. Chest 2009; 135: 1542-1549. 